\title{
PRIMARY AND SECONDARY DISLOCATION OF THE SCAPHOID BONE
}

\author{
T. Campbell Thompson, Rolla D. Campbell, Jun., and William D. Arnold \\ New York, United States of America
}

Injuries to the wrist often present problems of accurate diagnosis and effective treatment (MacAusland 1944, Böhler 1956, Cave 1958, Aitken and Nalebuff 1960). Those associated with fractures are usually demonstrated by proper radiographs, but even these injuries may be missed (Soto-Hall and Haldeman 1941, Speed 1950). Dislocation of the scaphoid bone may occur after apparently successful reduction of a major carpal dislocation or may occur as a primary condition.

We have seen nine patients with rotational dislocation of the scaphoid bone. In two the dislocation was easily recognised; in the other seven the diagnosis was not so easy. This type of dislocation, though it has been described before (Cave 1941, Watson-Jones 1955, McLaughlin 1959, Wagner 1959, Wade 1960), is easily recognised only if it is specifically sought. The purpose of this paper is to draw attention to the condition, which, if unrecognised and untreated, may cause significant disability.

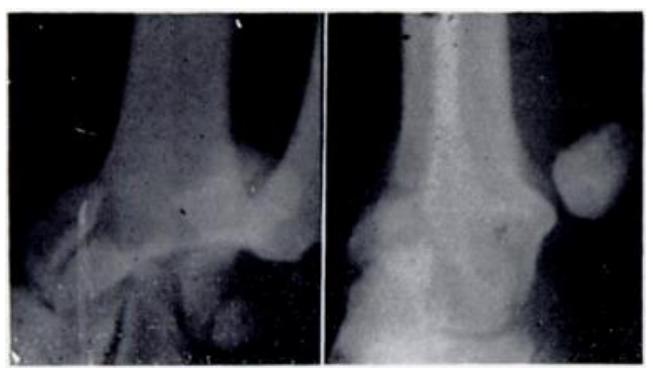

FiG. 1

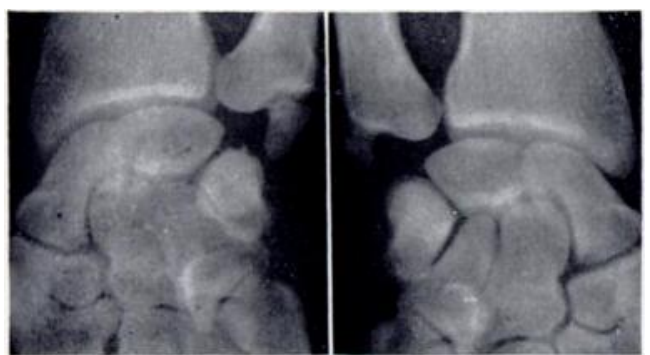

FIG. 3

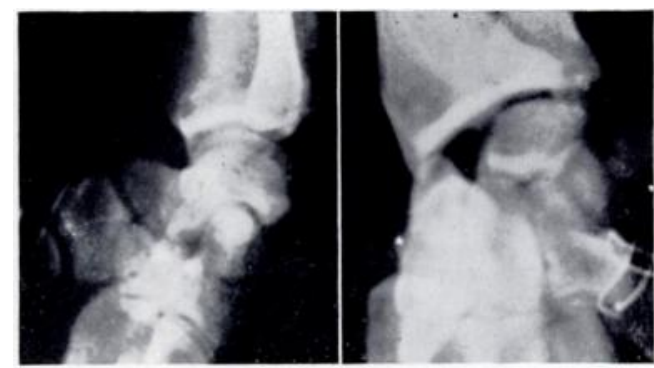

FIG. 2

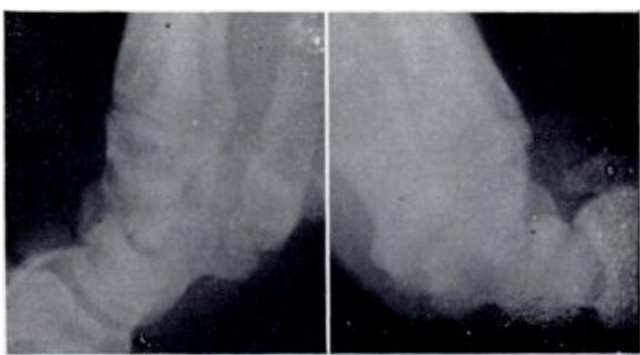

FIG. 4

Case 1-Residual dislocation of the scaphoid bone after major carpal dislocation. Figure 1-Radiographs showing severe dislocation of the proximal row of the carpus in a labourer of thirty-seven. Figure 2After open reduction and before the application of plaster. Note the persistent dislocation of the scaphoid bone. This dislocation was later reduced by manipulation. Figure 3-Ten months later: antero-posterior radiographs of injured wrist and of normal wrist (right) show normal relation between scaphoid and lunate bones and no evidence of avascular necrosis. Figure 4-Lateral radiographs in extension show residual stiffness of the radiocarpal joint on the affected side (left).

\section{CASE REPORTS}

Case 1-A labourer of thirty-seven suffered a severe dislocation of the proximal row of the left carpus (Fig. 1). Two attempts at closed reduction were unsuccessful and eventually the lunate bone was reduced by open operation through an anterior approach. Radiographs taken before the application of plaster showed that the dislocation of the scaphoid bone persisted (Fig. 2). This dislocation was 
reduced by manipulation. Radiographs taken ten months later showed normal relationship between the scaphoid and lunate bones and no evidence of avascular necrosis (Fig. 3). Although there was restriction of extension of the wrist by one-half and of flexion by one-third the patient had no pain or other symptoms and was doing heavy manual work one year after injury (Fig. 4).

Case 2-A Chilean rancher of thirty-nine injured his right wrist in a fight. The diagnosis of carpal dislocation was not made for two months, during which period the wrist was splinted in plaster. The lunate bone was then excised, but function of the wrist did not improve. He was seen nine months after injury, when he had marked pain and restriction of movement of the wrist. Radiographs showed obvious dislocation of the scaphoid bone (Fig. 5). Radio-capitate arthrodesis with excision of the remaining bones of the proximal row was done.

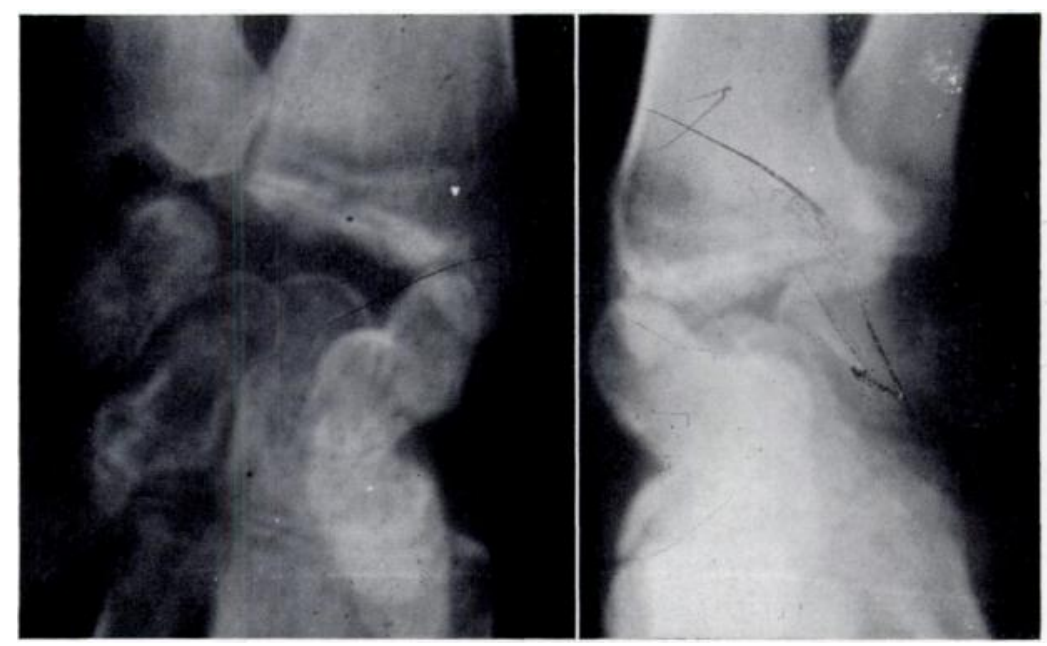

FIG. 5

Case 2-Antero-posterior and oblique radiographs of the right wrist of a man of thirty-nine, nine months after injury and seven months after removal of the lunate bone, showing residual dislocation of the scaphoid bone back wards and radially.

Case 3-An engineer of thirty injured his left wrist while ski-ing and suffered an anterior dislocation of the lunate bone (Fig. 6). Rotational dislocation of the scaphoid bone was seen in the radiographs taken soon after injury (Fig. 7). Manipulative reduction was done two hours after injury, with the patient under general anaesthesia. The wrist was immobilised in a plaster, which was removed by the patient two weeks after reduction. One month after injury the wrist was painful and rather stiff. Radiographs showed persistent dislocation of the scaphoid bone (Fig. 8). This dislocation was reduced by operation. At operation the wrist joint was opened through a posterior approach and scar tissue in the proximal row of carpal bones was excised. Reduction could then be achieved (Fig. 9). One year after operation the function of the wrist was excellent, but radiographs showed some widening of the space between the scaphoid and lunate bones (Fig. 10).

Case 4-A chiropractor of thirty fell down a lift shaft and injured his left wrist. He sustained a perilunar dislocation with rotational dislocation of the scaphoid bone (Fig. 11). Closed reduction under analgesia by brachial block was successful (Fig. 12). Plaster was applied. Six days later radiographs showed recurrence of the perilunar dislocation (Fig. 13). Reduction was again done, this time with the patient under general anaesthesia. Radiographs showed apparently satisfactory position, but there was some loss of height of the scaphoid bone (Fig. 14). However, the lateral radiographs of both wrists showed more or less similar appearances (Fig. 15). The wrist was splinted in moderate flexion for one month. Radiographs taken six weeks after injury showed residual rotational dislocation of the scaphoid bone (Fig. 16). Ten months after injury the patient had considerable stiffness of the left wrist, but had no pain and was working as a chiropractor.

Case 5-A floor waxer of fifty-six had his left wrist injured when a heavy machine knocked his hand against a wall. He suffered a fracture of the lower end of the radius with slight displacement. A plaster was applied and was kept on for three weeks. He was seen nine months later because of persistent pain in the wrist, which was only partly relieved by the wearing of a leather support. 
Radiographs of the wrist taken with the forearm fully pronated showed no abnormality, but those taken in supination showed widening of the space between the scaphoid and lunate bones. The lateral radiographs showed rotational dislocation of the scaphoid bone (Figs. 17 and 18). The patient refused further treatment.

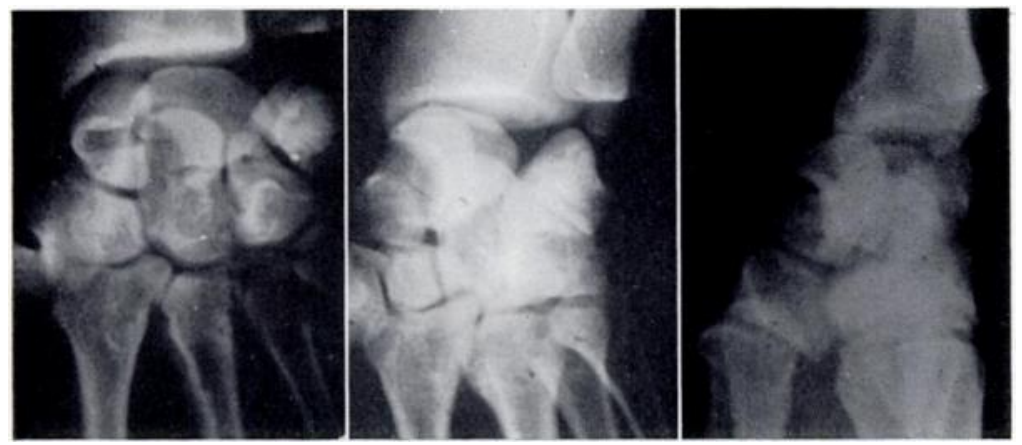

FIG. 6

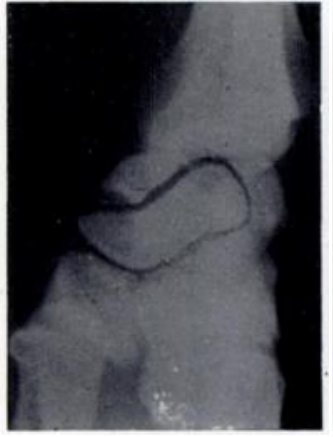

FIG. 7

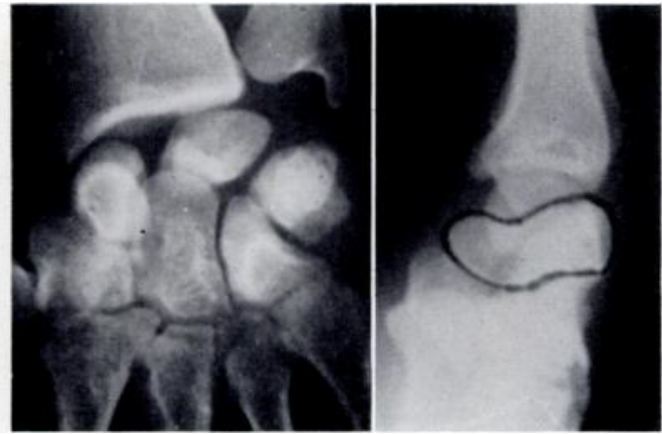

FIG. 8

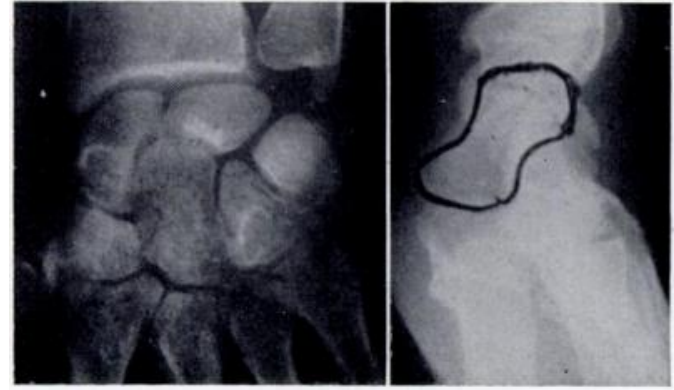

Fig. 9

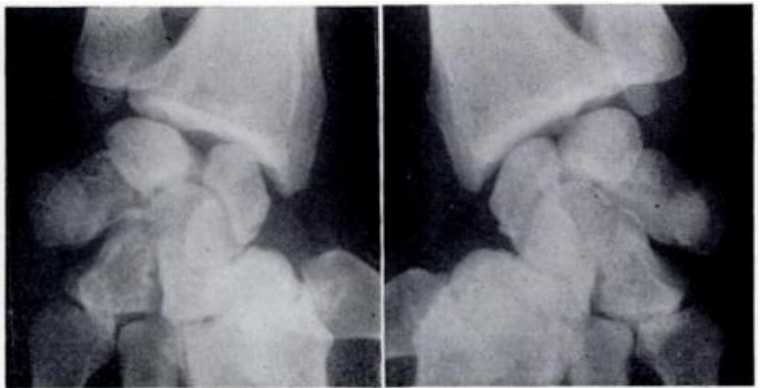

Fig. 10

Case 3-Residual dislocation of the scaphoid bone after carpal dislocation. Figure 6-Antero-posterior oblique and lateral radiographs of the left wrist of a man of thirty showing anterior dislocation of the lunate bone. Figure 7-Lateral radiograph with the scaphoid outlined. Note the abnormal orientation of the long axis of the scaphoid. Figure 8-One month after manipulative reduction. The antero-posterior view shows loss of height of the scaphoid and widening of the space between it and the lunate; the lateral view (right) shows persistently abnormal orientation of the long axis of the scaphoid. Figure 9-After open reduction. Note the restoration of the normal relation between the scaphoid and lunate bones and of the orientation of the long axis of the scaphoid. Figure 10-One year after operation: on full supination there is some widening of the space between the scaphoid and lunate bones of the injured wrist (left).

Case 6-A physician of seventy-nine fell downstairs and injured his left wrist. Radiographs showed a fracture of the posterior aspect of the lower end of the radius with alteration of the relationship between the capitate and lunate bones and apparent widening of the space between the scaphoid and lunate bones (Fig. 19). After fifteen minutes' fifteen-pound traction on the thumb and fingers with the aid of local analgesia closed reduction by flexion and extension of the wrist with pressure over the

VOL. 46 B, NO. 1, FEBRUARY 1964 


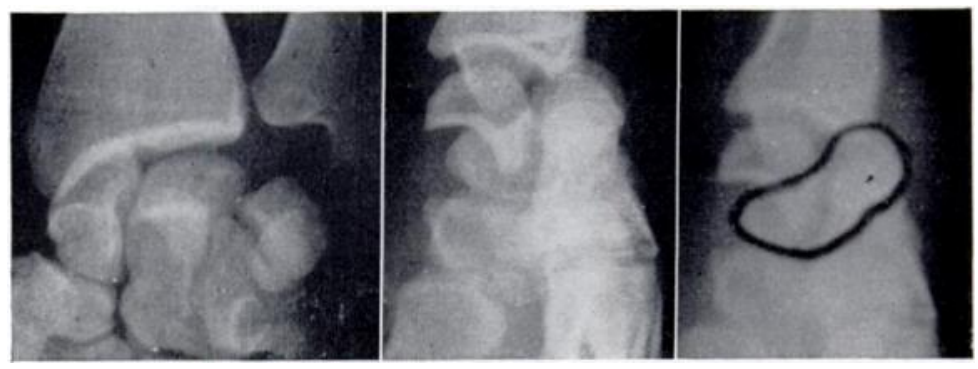

FIG. 11

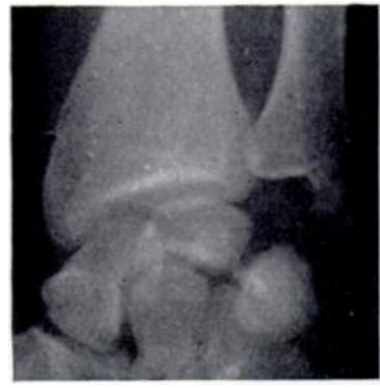

FIG. 12

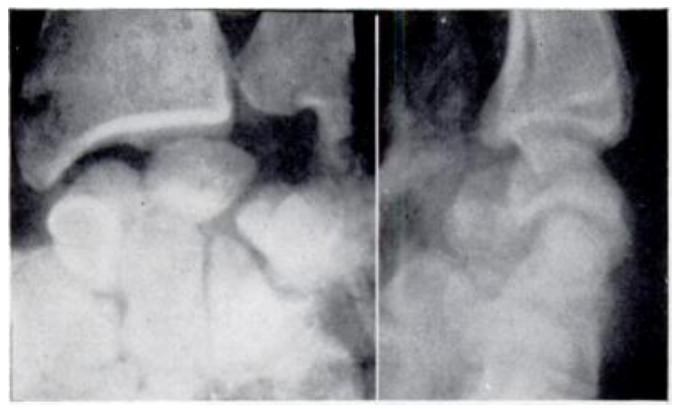

FIG. 14

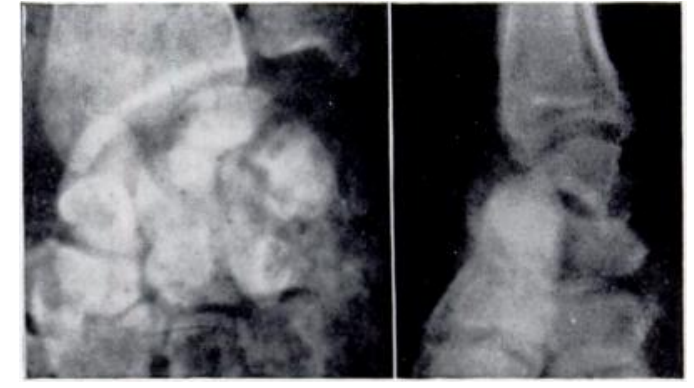

FIG. 13

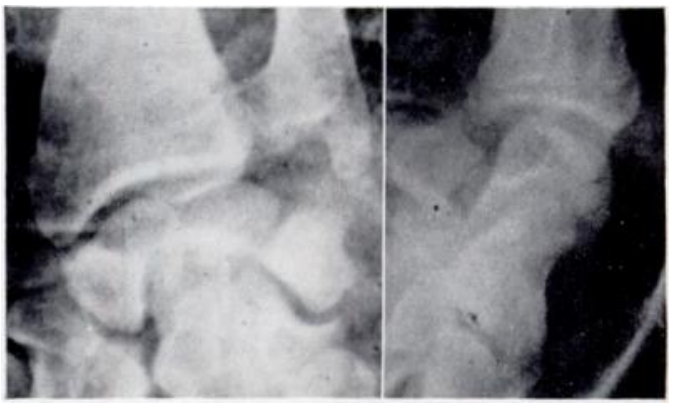

Fig. 15

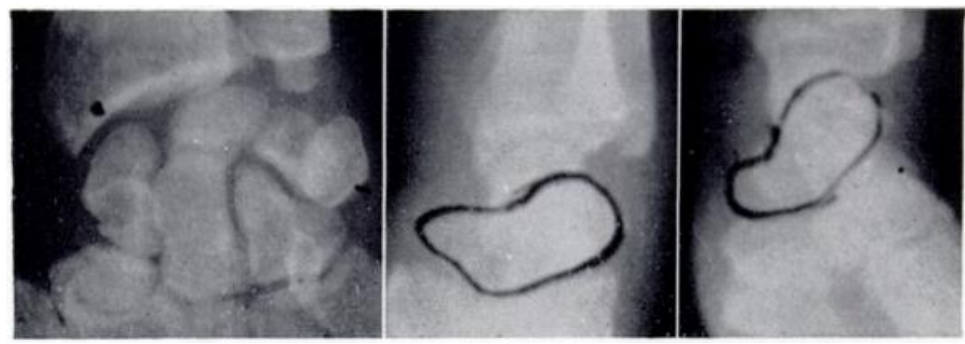

FIG. 16

Case 4-Residual dislocation of the scaphoid bone after carpal dislocation. Figure 11-Antero-posterior and lateral radiographs and lateral radiograph with the scaphoid outlined (right) of the left wrist of a man of thirty showing perilunar dislocation. Note the rotational dislocation of the scaphoid. Figure 12-After reduction; good reposition has been obtained. Figure 13-Six days later: the perilunar dislocation has recurred. Figure 14After second manipulative reduction. Good reposition has apparently been achieved, but there is a suggestion of loss of height of the scaphoid bone. Figure 15-Radiographs of the right wrist, which had suffered a minor fracture of the lower end of the radius. Note the normal height of the scaphoid. The appearance of the wrist in the lateral view is very similar to that of the left. Figure 16-Six weeks after injury. In the antero-posterior view the loss of height of the scaphoid and the widening of the space between it and the lunate are well shown. The abnormal flattening position of the scaphoid in the injured wrist is seen in the centre above as compared with the uninjured wrist on the right above. 

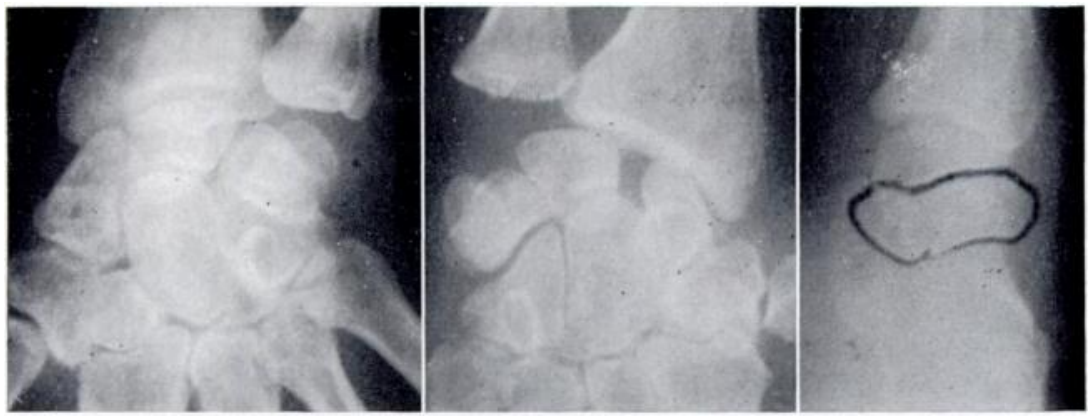

FIG. 17
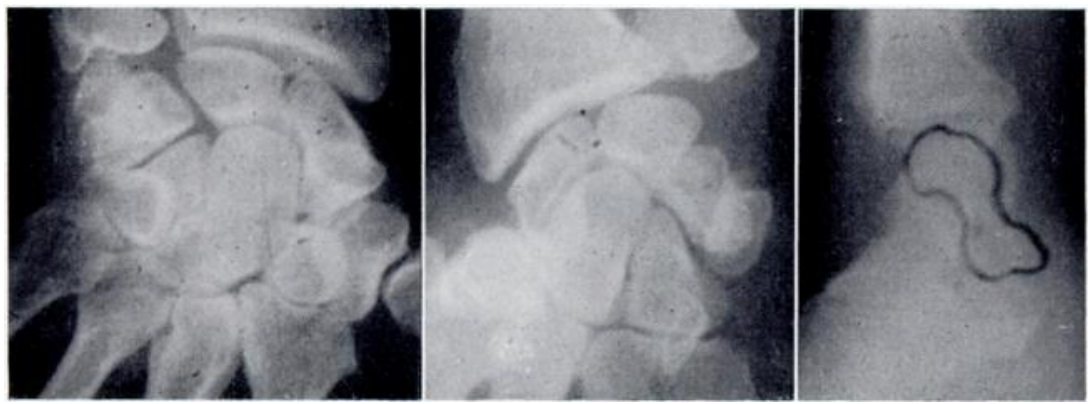

FiG. 18

Case 5-Rotational dislocation of the scaphoid associated with fracture of the lower end of the radius. Figure 17-Radiographs of the left wrist of a man of fifty-six, nine months after injury. Antero-posterior view in pronation (left) shows slight loss of height of scaphoid. In supination (centre) the widening of the space between the scaphoid and lunate bones is well shown. In the lateral view (right) the abnormality of the orientation of the long axis of the scaphoid is seen. Figure 18-Similar views of the right wrist for comparison.

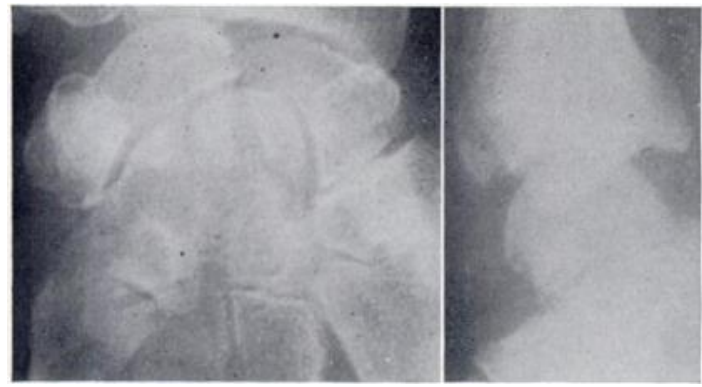

FIG. 19

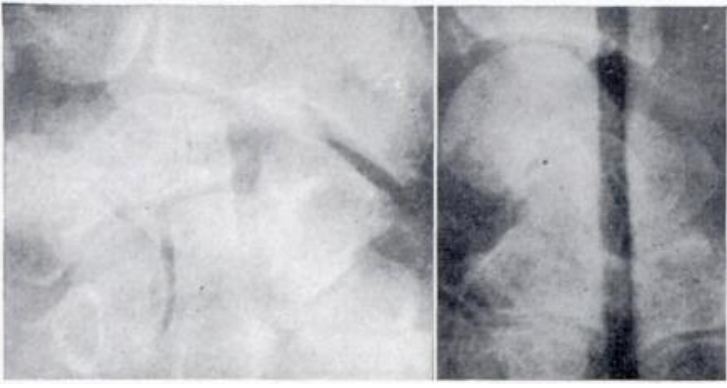

FIG. 21

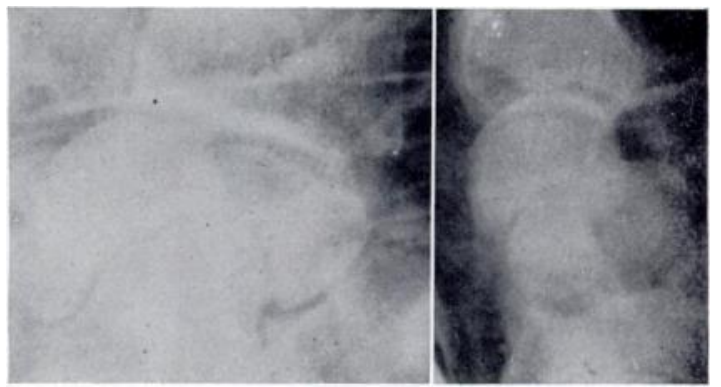

FIG. 20

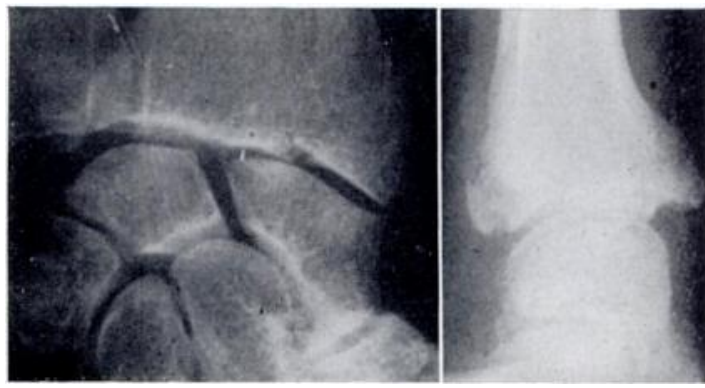

FIG. 22

Case 6-Dislocation of the scaphoid bone associated with fracture of the back of the lower end of the radius. Figure 19-Antero-posterior and lateral radiographs of the left wrist of a man of seventy-nine showing loss of height of the scaphoid and widening of the space between it and the lunate, together with a fracture of the lower end of the radius. Figure 20-After manipulative reduction. Satisfactory reposition has been obtained. Figure 21-The next day, after splitting of the plaster necessitated by swelling: recurrence of the rotational dislocation of the scaphoid. Figure 22-After final reduction: restoration of normal relationships.

VOL. 46 B, NO. 1, FEBRUARY 1964 
back of the carpus was successful (Fig. 20). A plaster was applied to hold the wrist in 30 degrees of flexion. The same night it became necessary to split the plaster, and the next day radiographs showed rotational dislocation of the scaphoid bone with widening of the space between it and the lunate (Fig. 21). Further attempts at reduction were deferred so that the patient could return to the care of his own doctor, Dr K. R. Manning, of Indianapolis. He secured reduction with the patient under general anaesthesia (Fig. 22).

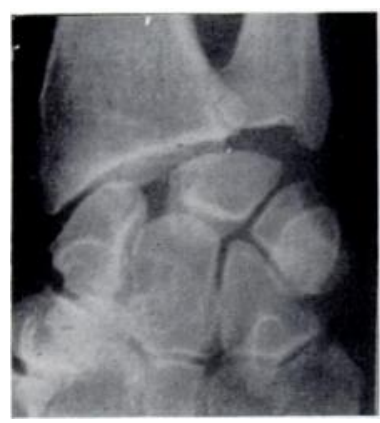

FIG. 23

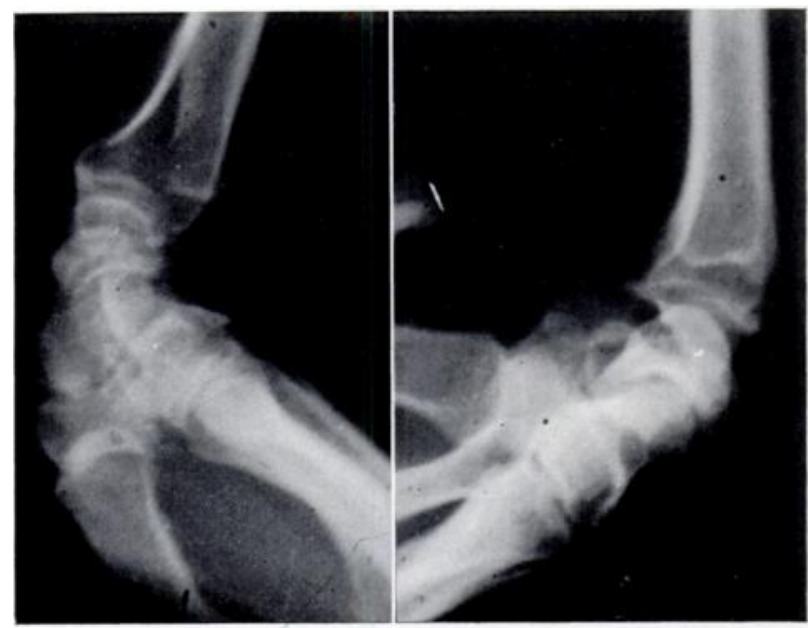

FIG. 25

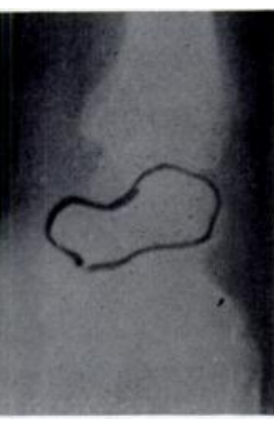

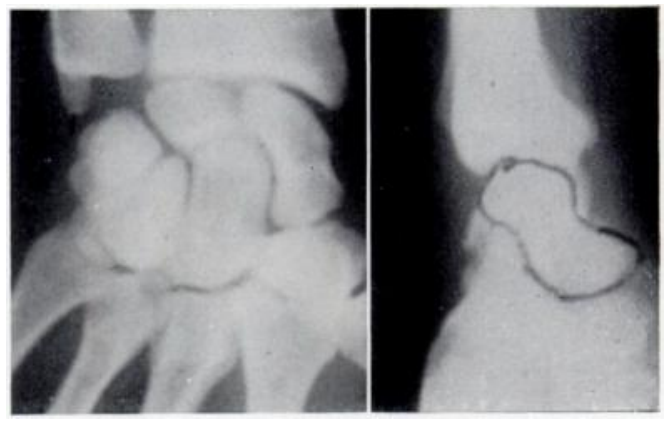

FIG. 24

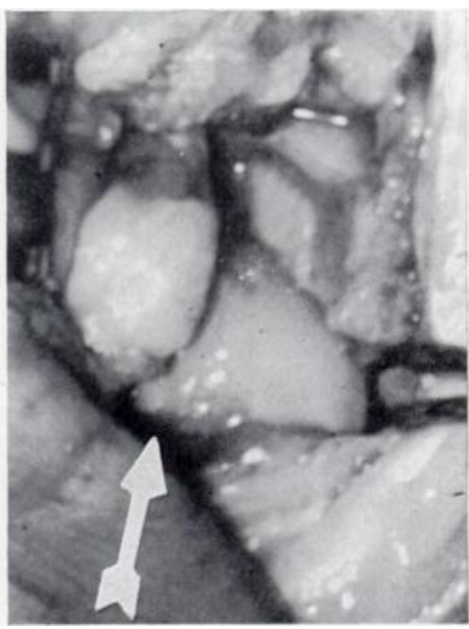

Fig. 26

Case 7-Rotational dislocation of the scaphoid bone caused by supination strain. Figure 23-Anteroposterior and lateral radiographs of the left wrist of a man of sixty taken some time after supination injury, showing loss of height of scaphoid, widening of the gap between it and the lunate, and alteration of the orientation of the long axis of the bone. Figure 24-Radiographs of the right wrist for comparison. Figure 25-Lateral radiographs of the left wrist in extension and flexion, showing relatively good range of movement. Figure 26-Findings at operation. The capitate bone (arrowed) is forcing the scaphoid and lunate bones apart. Also note that the scaphoid is displaced and rotated posteriorly presenting its articular surface, most of which should face the radius.

Case 7-A painter of sixty injured his left wrist when, while he was helping to carry a heavy cabinet with the forearm fully supinated, his mate dropped the other end. Pain and weakness persisted in spite of treatment by splinting, hydrocortisone injections and physiotherapy. Radiographs showed widening of the space between the scaphoid and lunate bones, loss of height of the scaphoid and rotational dislocation of this bone (Figs. 23 and 24). The range of movement was quite well preserved (Fig. 25). Open reduction was done. At operation the dislocation of the scaphoid was clearly seen, the capitate seeming to be forcing it and the lunate apart (Fig. 26). Reduction could not be maintained, so the proximal row of carpal bones was removed. Pain continued, although the range of movement and the strength were good, so ten months after the first operation radio-capitate arthrodesis was done. Fusion was achieved, but the patient continued to complain of pain. A complicating factor in this case was the related compensation claim. 
Case 8-A labourer of forty-five injured his right wrist in an attempt to catch a heavy bag dropped from above. Six years later he was still getting intermittent pain in the right wrist. There was one-half loss of flexion and extension was limited to 15 degrees, with tenderness over the back of the wrist at

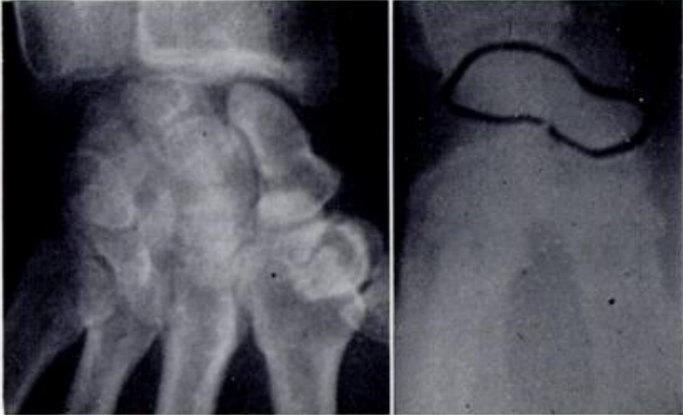

FIG. 27

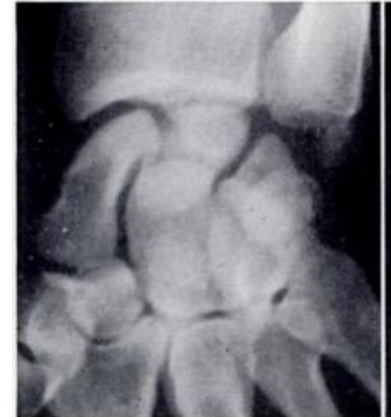

FIG. 28

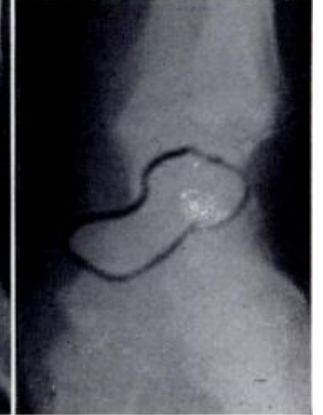

Case 8-Rotational dislocation of the scaphoid bone. Antero-posterior and lateral radiographs of right and left wrists (right) of a man of forty-five, six years after acute strain of the right. Note in the injured wrist (left) the loss of height of the scaphoid, the widening of the space between it and the lunate, and the abnormal orientation of the long axis of the bone.

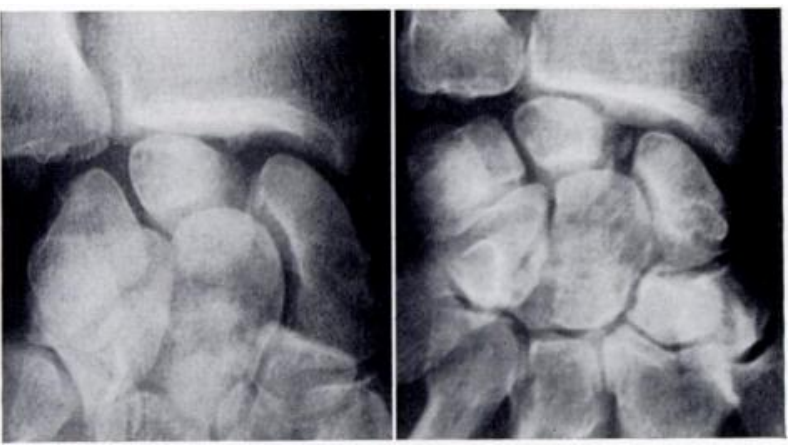

FIG. 29

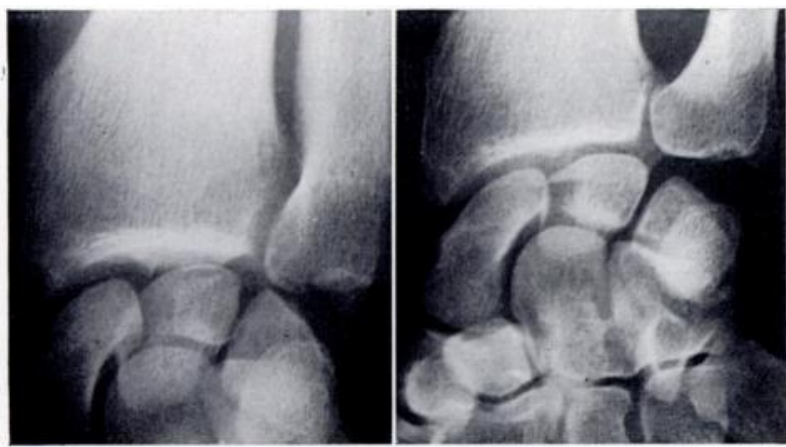

FIG. 31

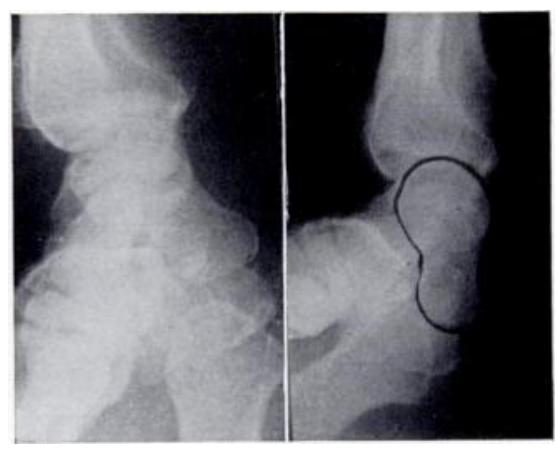

FIG. 30

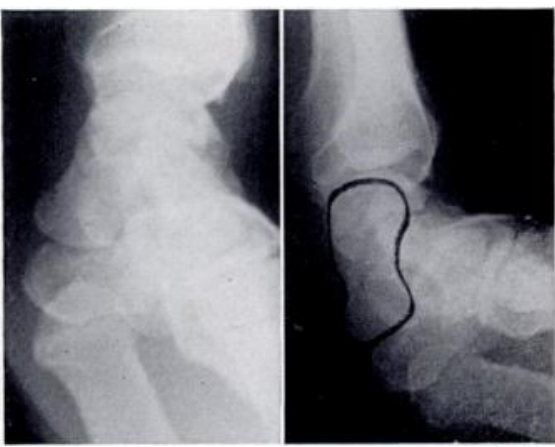

FIG. 32

Case 9-Rotational dislocation of the scaphoid without definite history of injury. Figure 29-Antero-posterior radiographs of the right wrist of a man of thirty-four in ulnar deviation and in radial deviation (right). In both views a flake of bone is seen in the widened space between the scaphoid and lunate bones; in radial deviation the loss of height of the scaphoid is well shown. Figure 30-Lateral radiographs in neutral position and in extension $($ right $)$. In extension the orientation of the scaphoid approaches normal. Figures 31 and 32-Similar views of the left wrist for comparison.

the base of the scaphoid. Radiographs showed some widening of the space between the scaphoid and lunate bones, some loss of height of the scaphoid and, in the lateral view, rotational dislocation of the scaphoid (Figs. 27 and 28). Arthrodesis of the wrist was done at another hospital.

VOL. 46 B, NO. 1, FEBRUARY 1964 
Case 9-A professional boxer of thirty-four was under treatment for delayed union of a fracture of a finger. He denied that he had any trouble in the wrist or that he had injured it at any time. The wrist showed full range of movement and excellent strength. Radiographs of the wrist taken in ulnar deviation showed little abnormality apart from some widening of the space between the scaphoid and lunate bones and the presence of a small piece of bone in this space (Fig. 29). However, radiographs taken in radial deviation showed obvious loss of height of the scaphoid, and lateral views taken in the neutral position clearly showed that there was rotational subluxation of this bone (Figs. 30 to 32 ). This rotational deformity was fully corrected in the extended position (Figs. 30 to 32).

\section{DISCUSSION}

Clinical aspects - In four of these cases of rotational dislocation of the scaphoid bone (Cases 1 to 4) the malposition of the scaphoid was a residual condition after major dislocation of the carpus. In two of these the dislocation of the scaphoid was severe and easily recognisable. In five (Cases 5 to 9) it occurred as an isolated carpal dislocation. In two of these it was associated with a fracture of the lower end of the radius, and in two it was not associated with any other bony injury. In one (Case 9) there was no history of injury, and the dislocation was only discovered incidentally.

Results of treatment-In the first of the first group of patients (Case 1) the dislocation was recognised and corrected at an early stage and an excellent result was obtained. In another (Case 3) open correction delayed as long as six weeks was followed by a good result. In one patient (Case 2) persistent symptoms from uncorrected dislocation led to arthrodesis, but the remaining patient (Case 4) had little trouble from the persistent displacement even though there was marked restriction of movement.

One patient (Case 6) with isolated dislocation of the scaphoid obtained a good result after early reduction, but the other patient (Case 5) coming under treatment much later, had persistent pain and weakness from the uncorrected dislocation although the range of movement was good. In another patient (Case 7) with isolated scaphoid dislocation, open reduction was attempted, but failed because of the impossibility of maintaining reduction. This patient and one other (Case 8 ) had persistent symptoms of such severity as to lead to arthrodesis. The patient (Case 9) with an isolated dislocation of the scaphoid that was only revealed incidentally had a strong and fully mobile wrist and clearly did not require treatment for this condition.

Physical signs-In all patients with uncorrected dislocation of the scaphoid bone in whom physical signs could be elicited from the affected wrist there was loss of extension of the joint and tenderness over the back of the wrist in the region of the radio-scaphoid joint. Occasionally a click could be felt in this region on extension of the wrist.

Radiological signs-The important radiological features were 1) loss of height of the scaphoid bone in the antero-posterior projection, 2) widening of the space between the scaphoid and lunate bones, occasionally with interposition of the capitate bone, and 3) a more horizontal disposition of the long axis of the scaphoid as seen in the lateral projection.

Radiological diagnosis is aided by certain modifications of technique: 1) the cone should be centred over the affected wrist and over the healthy one separately so as to bring the carpus into sharper profile in each wrist. 2) Special care should be taken to place the wrists in strictly comparable positions of rotation, and to take views in full supination and in full pronation. Often the widening of the space between the lunate and scaphoid bones is only seen in the view taken in full supination. 3) Antero-posterior projections should be taken with each wrist in full ulnar and in full radial deviation: often the loss of height of the scaphoid bone is only seen in the view taken in full radial deviation. 4) Outlining the scaphoid in the lateral projection with the mark of a wax pencil shows more plainly its loss of height and its tendency to posterior dislocation. 


\section{OTHER WORKERS' EXPERIENCE}

Mechanism of injury-Wilson and Cochrane (1925) stated that dislocation of a single carpal bone, other than the lunate, was a rare occurrence. They suggested that occasionally posterior rotational dislocation of the scaphoid was caused by flexion strain. Bunnell (1948), however, inferred that this dislocation was caused by extension strain.

Connell and Dyson (1955) reviewed reported cases of acute waist-deep scaphoid dislocation and found that it occurred when the hand gripped an object with the wrist in a position of extension and ulnar deviation. They thought that if the wrist had been in a neutral position the force would have been transmitted through the capitate bone to cause perilunar dislocation. Their summary included reports by Andrews (1932), Buzby (1934), Kuth (1939), Walker (1943) and Russell (1949). In all but Walker's case, closed reduction was achieved. Walker had to remove the scaphoid bone completely before reduction could be achieved, but the bone was stable in good position after reduction. Six weeks later there was radiological evidence of avascularity of the scaphoid bone, but at seven months movements of the wrist were only limited by a few degrees in extension. In none of the other cases of similar dislocation of the scaphoid was there evidence of avascularity of the bone.

Cave (1941) showed how in perilunar dislocation the scaphoid has to rotate so that its tubercle points to the palm as the capitate dislocates backward on the lunate. Either rotation or fracture has to occur to permit this movement; in Cave's view the former was the more frequent occurrence.

Vaughan-Jackson (1949) described " dart-thrower's wrist "-rotational dislocation of the posterior pole of the scaphoid produced by snapping movements, and initially caused by a sprain of the wrist sustained during a game of rugby.

McLaughlin (1959) described carpal instability occurring many months after reduction of a perilunar dislocation. There was rotational dislocation of the scaphoid causing the proximal pole to project backwards and to impinge against the radius so as to impede extension of the wrist. In the antero-posterior projection widening of the space between the scaphoid and lunate was seen. Balensweig and Balensweig (1960) described a case of post-traumatic arthritis of the wrist after rotational dislocation of the scaphoid and suggested that the dislocation had originally been complete, and that there had been partial spontaneous reduction to leave residual rotation of the scaphoid. The same suggestion was made by Wagner (1959) who stated that in cases of isolated dislocation of the scaphoid careful examination usually showed a loss of normal relationship between the capitate and lunate bones that indicated that there was really a perilunar dislocation. He further stated that the perilunar dislocation must be reproduced in order to permit the return of the proximal pole of the scaphoid.

Results of treatment-Russell (1949) described one case of scaphoid dislocation seen some time after injury, and three cases of recurrent subluxation. In the first case the wrist did well after closed reduction. In one case of recurrent subluxation a good result followed fusion of the scaphoid to the lunate, and in another there was improvement after manipulation and a short period of immobilisation. In the last case a poor result followed removal of the scaphoid bone.

Watson-Jones (1955) reported two cases in which recurrent subluxation was stopped by reefing the posterior capsule. He also listed five cases of acute dislocation of the scaphoid bone and stated that occasionally operation was required in order to release interposed capsule.

\section{SUMMARY}

1. Nine cases of disturbance of the relationship between the scaphoid and the radius and between the scaphoid and the lunate bones are described.

2. Persistent dislocation of the scaphoid bone may follow reduction of perilunar dislocations or of other dislocations of the proximal row of the carpus. It may be obvious, as in waist-deep dislocation, or may be solely a rotational dislocation which may be difficult to diagnose.

vol. $46 \mathrm{~B}$, NO. 1, FEBRUARY 1964 
3. Uncorrected rotational dislocation of the scaphoid bone caused significant disability in six of seven cases.

4. Aids to the diagnosis of this condition are described and a vigorous approach to the problem of correction is advocated.

5. The experience of other workers in this field is reviewed and discussed.

\section{REFERENCES}

Aitken, A. P., and Nalebuff, E. A. (1960): Volar Transnavicular Perilunar Dislocation of the Carpus. Journal of Bone and Joint Surgery, 42-A, 1,051.

Andrews, F. T. (1932): A Dislocation of the Carpal Bones-The Scaphoid and Semilunar: Report of a Case. Journal of the Michigan State Medical Society, 31, 269.

Balensweig, H. D., and Balensweig, I. (1960): In Surgical Treatment of Trauma, p. 495. Edited by P. A. Wade. New York: Grune and Stratton.

BöHLER, L. (1956): The Treatment of Fractures, p. 827. New York: Grune and Stratton.

Bunnell, S. (1948): Surgery of the Hand. Second edition, p. 681. Philadelphia and London: J. B. Lippincott Company.

Buzby, B. F. (1934): Isolated Radial Dislocation of Carpal Scaphoid. Annals of Surgery, 100, 553.

CAVE, E. F. (1941): Retrolunar Dislocations of the Capitate with Fracture or Subluxation of the Navicular Bone. Journal of Bone and Joint Surgery, 23, 830.

CAve, E. F. (1958): Fractures and Other Injuries, p. 376. Chicago: The Year Book Publishers.

Connell, M. C., and Dyson, R. P. (1955): Dislocation of the Carpal Scaphoid. Journal of Bone and Joint Surgery, 37-B, 252.

Cooper, Sir Astley (1832): A Treatise on Dislocations and on Fractures of the Joints, p. 474. Boston: Lilly and Wait, and Carter and Hendee.

Kuth, J. R. (1939): Isolated Dislocation of the Carpal Navicular: A Case Report. Journal of Bone and Joint Surgery, 21, 479.

MacAusland, W. R. (1944): Perilunar Dislocation of the Carpal Bones and Dislocation of the Lunate Bone. Surgery, Gynecology and Obstetrics, 79, 256.

Mclaughlin, H. L. (1959): Trauma, p. 140. Philadelphia and London: W. B. Saunders Company.

Russell, T. B. (1949): Inter-Carpal Dislocations and Fracture-Dislocations. Journal of Bone and Joint Surgery, 31-B, 524.

SchlossBach, T. (1954): Dislocation of the Carpal Navicular Bone not Associated with Fracture. Journal of the Medical Society of New Jersey, 51, 533.

Soto-Hall, R., and Haldeman, K. O. (1941): The Conservative and Operative Treatment of the Carpal Scaphoid (Navicular). Journal of Bone and Joint Surgery, 23, 841.

SPEED, K. (1950): Fractures and Dislocations of the Carpus. California Medicine, 72, 93.

VAughan-JACKSON, O. J. (1949): A Case of Recurrent Subluxation of the Carpal Scaphoid. Journal of Bone and Joint Surgery, 31-B, 532.

WaDE, P. A. (1960): Surgical Treatment of Trauma. New York: Grune and Stratton.

WaGner, C. J. (1959): Fracture-Dislocationc of the Wrist. Clinical Orthopaedics, 15, 181.

Walker, G. B. W. (1943): Dislocation of the Carpal Scaphoid Reduced by Open Operation. British Journal of Surgery, 30, 380.

WATSON-JONES, Sir R. (1955): Fractures and Joint Injuries. Fourth edition, p. 620. Baltimore: Williams and Wilkins Co.

Wilson, P. D., and Cochrane, W. A. (1925): Fractures and Dislocations, p. 304. Philadelphia and London: J. B. Lippincott Company. 